\title{
An Automatic Logistics System Using Artificial Intelligence
}

\author{
Jino Bae, Sana Lee, Siyu Kim, Yonghee Lee*
}

\begin{abstract}
In this paper, we propose a method to utilize machine learning to automate the system of classifying and transporting large quantities of logistics. First, establish an environment similar to the task of transferring logistics to the desired destination, and set up basic rules for classification and transfer. Next, each of the logistics that need sorting and transportation is defined as one entity, and artificial intelligence is introduced so that each individual can go to an optimal route without collision between the objects to the destination. Artificial intelligence technology uses artificial neural networks and uses genetic algorithms to learn neural networks. The artificial neural network is generated by each chromosome, and it is evolved based on the most suitable artificial neural network, and a score is given to each operation to evaluate the fitness of the neural network. In conclusion, the validity of this algorithm is evaluated through the simulation of the implemented system.
\end{abstract}

Keywords: Logistics, transportation, artificial intelligence, artificial neural network, genetic algorithm.

\section{Introduction}

With the spread of smartphones, mobile shopping has expanded and the worldwide courier market continues to grow. In particular, the domestic courier industry has been growing steadily due to the effects of e-commerce and TV home shopping since 2000's. Recently, it has exploded once again due to the generalization of mobile shopping using smartphones $[1,2]$. Courier market is growing at double-digit rates every year, especially in the US and China. Courier delivery has been positioned as a life-style service for the public.

The growth of the courier market is expected to continue in the future thanks to the emergence of various order delivery markets and changes in customer consumption patterns. However, due to excessive logistics growth due to the continuous growth of the logistics market, we are in danger of delivery delays, logistics damage, and misappropriation due

Revised Manuscript Received on July 05, 2019.

Jino Bae

Dept. of computer engineering, Halla University

Sana Lee

Dept. of computer engineering, Halla University

Siyu Kim

Dept. of computer engineering, Halla University

Yonghee Lee

Dept. of computer engineering, Halla University to lack of labor for sorting hub terminals, lack of land for delivery facilities. Therefore, automated logistic sorting and transfer has been used as a way to overcome this problem $[3,4]$. Research has also been conducted on introducing expert systems to classify and transport logistics [5]. In addition, Kiva Robots is used in Amazon for classifying and transporting logistics, and Alibaba develops and utilizes Quicktron Robots. Since these robots operate by a fixed algorithm, they have problems that are not suitable in various logistics environments and complex environments. In this study, we develop the algorithm of logistics transportation system which is improved through learning in various environments using artificial intelligence. Each entity can be classified into smart cell equipped with artificial intelligence, so that logistics sorting and transportation can be effectively performed.

\section{Methods}

\section{A. Algorithm Environment Design}

In order to construct a simulation environment for logistics classification and transportation, a destination is set in an arbitrary warehouse, and an object for classification and transportation is defined as a smart cell. The following rules apply to multiple smart cells.

Rule1: Smart cells move back and forth.

Rule2: Each smart cell has one individual destination.

Rule3: Avoid collision between smart cells

Rule4: The path for smart cell sorting and migration ensures that the entire smart cell path is minimized.

The artificial intelligence applied to this smart cell uses artificial neural network and genetic algorithm is applied to the learning algorithm of neural network.

\section{B. Artificial intelligence design}

The artificial intelligence techniques used in the experiments are artificial neural networks and genetic algorithms. Artificial neural network is a statistical learning algorithm that is inspired by neural

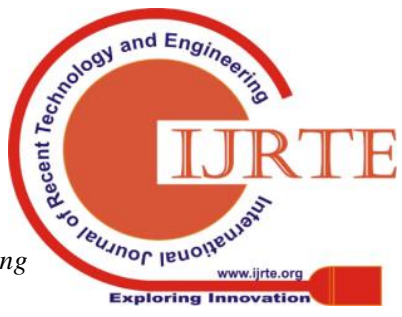


networks in machine learning and cognitive science. In this study, four input layers that know the location of the destination are given, and each input layer is compared with the destination Respectively. The first hidden layer determines which path to select if there are two possible directions in the input layer. If the second hidden layer has a different object or destination in the direction that the object can go, the weight You decide how to weaken the value. In this way, the four input layers go through two hidden layers into four output layers, and the final value is calculated by the soft max function. The process moves to the position determined as the optimal path from the calculated value. The overall process is shown in Fig.1

The genetic algorithm that learns the neural network is a computational model based on the evolution of the natural world. In this experiment, if there is an appropriate value for each hidden layer, the object will not collide. If the collision occurs, the fitness is stored in the collision chromosome, I go over. The number of chromosomes that are set up in this process is measured and passed to the next generation. The next generation, we select two chromosomes with the highest fitness of the previous generation. In this experiment, we use 'rank based selection'. The key to genetic algorithms is the occurrence of mutations so that they do not fall into local optimal solutions. A mutation modifies a gene on any chromosome and has a greater impact on the next generation if the chromosome shows a better fit. In this experiment, evolution rate was set to $0.05 \%$.

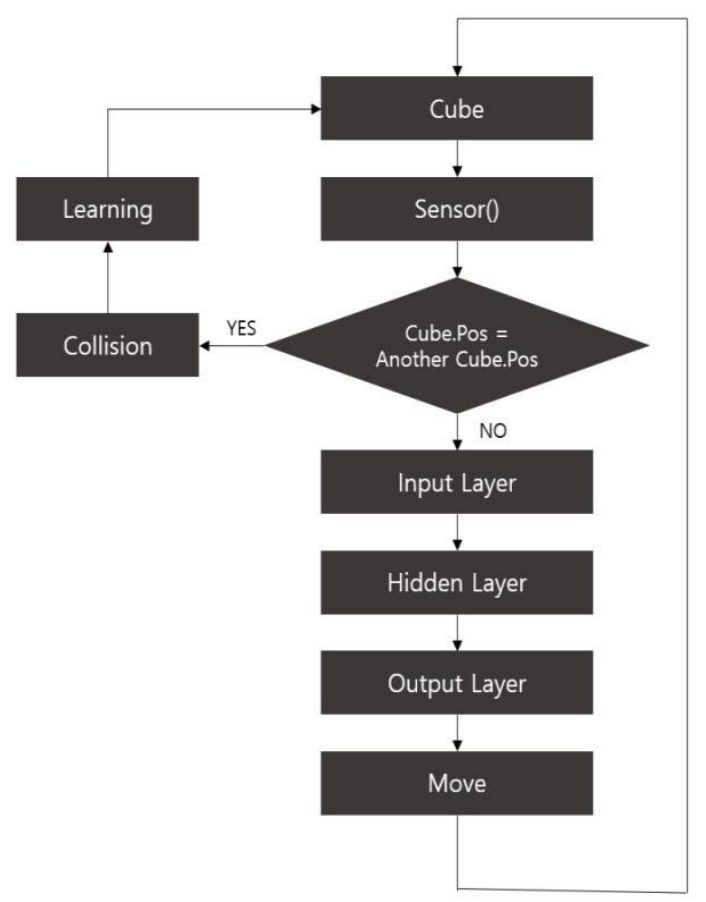

Fig.1. Overall Artificial Intelligence Process

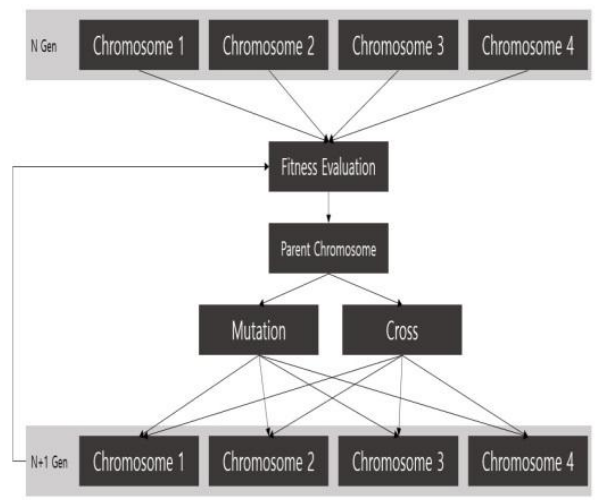

Fig.2. Genetic algorithm

\section{Experiments}

In the experiment, we created several objects and provided different destinations for each object. Then, a sensor for each object is installed as shown in Fig. 3, and the object is moved to the destination as shown in Fig. Also, in order to prevent collision between entities, it is necessary to provide positions of other entities and other entities in each operation, so that when the entities of other entities and entities exist in the direction of each entity in the value generated by the input layer, It moves in a direction in which it can go toward the destination without colliding with the collision. Appropriate weights to avoid collisions are calculated through genetic algorithms. A total of 11 genes were set up on the chromosome as shown in Fig. Each of the chromosomes evaluates the appropriateness of the computation and fitness, and the two chromosomes with high fitness become the parent chromosomes and generate the next generation. For example, a chromosome with high fitness is selected by giving 1 point for every surviving frame, 10 points for reaching the destination, -200 points for the infinite loop, and -100 for the collision.

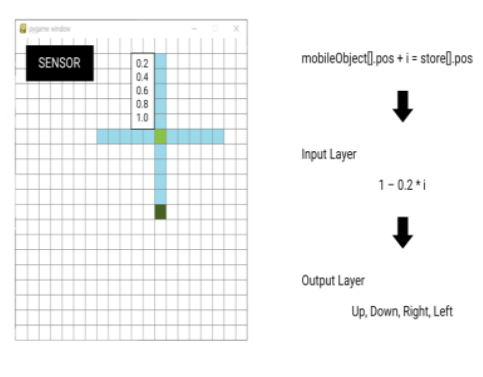

Fig.3. Input layer design of

artificial neural network 


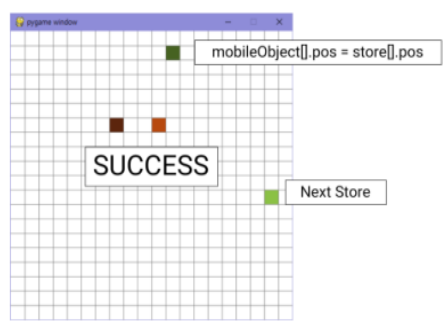

Fig.4. Design of basic rules

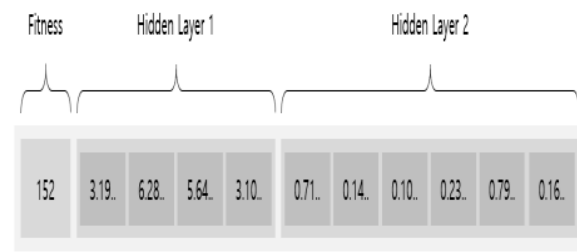

Fig.5. Chromosome design

\section{Results}

IN ORDER TO CONSTRUCT LOGISTICS CLASSIFICATION AND AUTOMATIC TRANSFER SYSTEM UTILIZING ARTIFICIAL INTELLIGENCE, WE CREATED A SIMULATION ENVIRONMENT SIMILAR TO THE ENVIRONMENT OF THE LOGISTICS SYSTEM AND SET UP BASIC RULES. WE CONSTRUCTED A SYSTEM TO ADAPT TO THE RULES USING ARTIFICIAL NEURAL NETWORKS AND USED GENETIC ALGORITHMS TO LEARN THE WEIGHTS OF ARTIFICIAL NEURAL NETWORKS. THEN, CHROMOSOMES WITH HIGH FITNESS ARE COMBINED TO CREATE A GENERATION WITH HIGHER FITNESS. FIGURE 6 SHOWS THE SIMULATION PROCESS. TABLE 1. SHOWS THE WEIGHT OF THE CHROMOSOME WITH THE HIGHEST FITNESS AMONG THE 100 CHROMOSOMES AS A RESULT OF THE EXECUTION OF THE FIGURE 6

\section{Conclusions}

The problem of shortage of manpower, which is a big problem in the logistics industry, can be solved through the logistics automation system using artificial intelligence and machine learning. Similar technologies include Amazon's KIVA and Alibaba's Quicktron Robots. Our experiment differs from the above technique in that 'KIVA' only performs operations within the specified path, whereas in this study, the smart cell can freely navigate to the destination within the two dimensional space. In addition, it has an advantage of scalability as an algorithm that can be applied to various classification and transportation fields as well as logistics, by carrying out an optimal route prediction by carrying an artificial intelligence.

\section{References}

[1]Dolati Neghabadi, Parisa, Evrard Samuel, Karine E., "Systematic literature review on city logistics: overview, classification and analysis", International journal of production research, Vol.57 No.3, 2019.

[2]Simic, D., Milutinovic, D., Simic, S., Suknaja, V., "Hybrid Patient Classification System in Nursing Logistics Activities", Lecture Notes in Computer Science, Vol.- No.6679, 2011.

[3]Lees, B., Neumann, G., Ziems, D., "Supporting Students' Learning of Logistics through the Application of Artificial Intelligence", ED MEDIA -PROCEEDINGS-, Vol.2 No.-, 1999.

[4] Vahdani, B., Dehbari, S., Naderi-Beni, M., Zeinali, "An artificial intelligence approach for fuzzy possibilistic-stochastic multi-objective logistics network design, NEURAL COMPUTING AND APPLICATIONS, Vol.25 No.7-8, 2014.

[5]Gunasekaran, A., Ngai, E. W. T., "Expert systems and artificial intelligence in the 21 st century logistics and supply chain management", Expert systems with applications, Vol.41 No.1, 2014

\begin{tabular}{|c|c|c|c|c|c|c|c|c|c|c|c|}
\hline & $\begin{array}{l}\text { Weight } \\
1-1\end{array}$ & $\begin{array}{l}\text { Weight } \\
1-2\end{array}$ & $\begin{array}{l}\text { Weight } \\
1-3\end{array}$ & $\begin{array}{l}\text { Weight } \\
1-4\end{array}$ & $\begin{array}{l}\text { Weight } \\
2-1\end{array}$ & $\begin{array}{l}\text { Weight } \\
2-2\end{array}$ & $\begin{array}{l}\text { Weight } \\
2-3\end{array}$ & & & & Finess \\
\hline Generation1 & 9.2689 & 2.8819 & 5.6587 & 6.2803 & 0.2666 & 0.7328 & 0.7821 & & & $19 \mathrm{H}$ & Koreq \\
\hline Generation2 & 5.223 & 2.8819 & 7.2233 & 6.2803 & 0.2406 & 0.7328 & 0.0241 & & & $41 \mathrm{H}$ & profeles \\
\hline Generation3 & 5.223 & 8.5409 & 7.2233 & 6.2803 & 0.0557 & 0.7328 & 0.7821 & & & & \\
\hline Generation4 & 5.223 & 8.5409 & 7.2233 & 6.2803 & 0.2406 & 0.9973 & 0.0241 & & & & \\
\hline Generation5 & 5.223 & 8.5409 & 7.2233 & 6.2803 & 0.2406 & 0.7328 & 0.0241 & & & 41 & -39.31 \\
\hline Generation6 & 5.223 & 8.5409 & 7.2233 & 8.0257 & 0.2406 & 0.7328 & 0.0241 & \multicolumn{4}{|c|}{ Jibro $\$$ Be,, Sana0ke, Siyu6K } \\
\hline Generation7 & 5.223 & 8.5409 & 7.2233 & 6.2803 & 0.2406 & 0.0424 & 0.0241 & re.6s: & $\mathrm{d}_{0 .} \mathrm{B}_{4.8}$ & Degige & $\operatorname{im}_{1} 1801$ \\
\hline Generation8 & 4.1609 & 8.5409 & 7.2233 & 6.2803 & 0.2406 & 0.7044 & 0.0241 & 4nisy & id $8 y_{3} 4 \mathrm{~K}$ & reg.eggin & 2032.91 \\
\hline Generation9 & 0.9803 & 8.5409 & 7.2233 & 6.2803 & 0.2406 & 0.649 & 0.0241 & 0.4745 & 0.6348 & 0.2791 & -35.86 \\
\hline Generation 10 & 4.1609 & 8.5409 & 7.2233 & 6.2803 & 0.2406 & 0.7044 & 0.0241 & 0.4745 & 0.6348 & 0.2791 & -46.93 \\
\hline
\end{tabular}

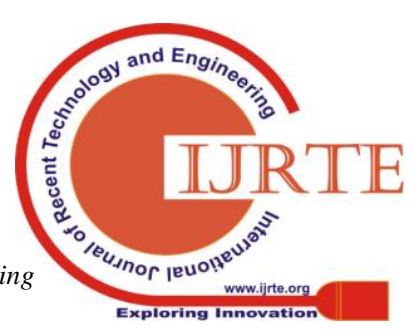

